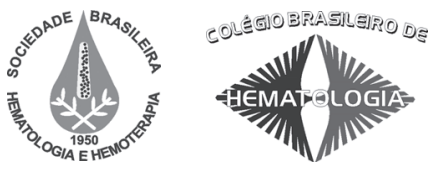

Revisão / Review

\title{
Terapia celular nas doenças oftalmológicas
}

\section{Cell therapy in ophthalmology diseases}

Rubens C. Siqueira

\section{Introdução}

Recentes avanços no campo da pesquisa das célulastronco têm voltado suas atenções na aplicação da terapia celular para regenerar tecidos oculares que têm sido danificados por uma doença degenerativa ou injúria. Alguns estudos, inclusive clínicos, têm demonstrado a viabilidade de se utilizarem as células-tronco para reparar ou regenerar o epitélio da córnea. ${ }^{1}$ É compreensível que a superfície da córnea consiste em uma área anatômica fácil para utilização da terapia celular, pois estas células poderiam ser implantadas sem usar métodos invasivos. Entretanto, outros tecidos oculares como a retina e epitélio pigmentado da retina (EPR) consistem em estruturas complexas responsáveis pela função visual e que a terapia celular ainda apresenta diversos problemas a serem resolvidos para a sua aplicabilidade.

Diferentes partes do olho derivam de diferentes tipos de tecido embrionário: a retina neurossensorial e o EPR têm origem neuroectoderma; a esclera, córnea e úvea originam do mesoderma, e o cristalino, do ectoderma. ${ }^{2}$ Portanto, a regeneração de diferentes tecidos oculares possui um grande desafio devido à sua diversidade e também na complexidade de sua via neural representada pelas células da retina e nervo ótico. Neste contexto, a viabilidade da regeneração pode depender da complexidade dos tecidos a serem reparados. Por exemplo, a regeneração do EPR pode consistir em um alvo relativamente fácil para as células-tronco por ser uma simples monocamada de células. A retina neural, entretanto, pode re-

Professor responsável pela disciplina de Oftalmologia da Faculdade de Medicina de Catanduva-SP. Professor Colaborador da USP-SP.

Centro de Pesquisa Rubens Siqueira - São José do Rio Preto-SP.

Correspondência: Rubens Camargo Siqueira

Rua Saldanha Marinho 2815, sala 42

15010-100 - São José do Rio Preto-SP - Brasil

E-mail:rubenssiqueira@terra.com.br

Doi: $10.1590 /$ S1516-84842009005000029 
querer protocolos mais complexos para sua regeneração, pois apresenta multicamadas formadas de neurônios e células gliais. Durante uma fase inicial da doença, a regeneração de um tipo de célula neural atingida pode ser mais fácil do que em um estágio mais avançado da doença onde outros tipos de neurônios foram comprometidos. Qualquer situação de reparo e regeneração das células da retina não necessitará somente do entendimento do mecanismo molecular que promove a diferenciação em neurônios funcionais e glia, mas também dos requisitos para uma bem sucedida migração, integração e sobrevida das células transplantadas. Isto é de uma importância especial, pois a retina, quando em um processo de sofrimento e tentativa de reparo, pode ter perdido a integridade neural, exibindo componentes inflamatórios e gliais que poderiam dificultar a regeneração das células transplantadas. Neste trabalho nós resumimos os resultados obtidos, até o momento, da utilização das células-tronco para reparo e regeneração dos tecidos oculares e também possíveis soluções para vencer os obstáculos no caminho da restauração visual baseado na terapia celular.

\section{Células-tronco e o desenvolvimento da retina}

É de conhecimento, há tempos, que peixes e anfíbios têm a habilidade de regenerar a retina neural através da vida e que as células-tronco capazes de regenerar a retina nestas espécies estão localizadas na margem ciliar. $^{3}$ A presença de células-tronco na margem ciliar da retina foi também documentada em algumas aves e pequenos mamíferos ${ }^{4}$ e, mais recentemente, estudos têm identificado células-tronco da retina na mesma região no olho humano. ${ }^{5}$ Além disso, as células gliais de Müller têm mostrado ter um potencial para regenerar novos neurônios em resposta a um dano agudo na retina de filhotes de aves ${ }^{6}$ e ratos. ${ }^{7}$ A característica neurogênica exibida pelas células gliais de Müller no olho adulto tem sido demonstrada no peixe (zebrafish), a glia da Müller forma um nicho de células-tronco e elas são hábeis em gerar células-tronco retinianas após uma injúria local. ${ }^{8}$ Outro aspecto interessante é que investigações mais recentes têm identificado uma população de células gliais de Müller com característica de células-tronco na retina humana de adulto, ${ }^{9}$ o que sugere que a retina humana, semelhante à do zebrafish, pode ter um potencial para regeneração.

Durante o desenvolvimento, as células gliais de Müller e os neurônios da retina compartilham de um progenitor comum que é multipotente para todos os estágios da histogênese da retina. ${ }^{10}$ Esta evidência deriva do exame da característica de uma célula progenitora de um camundongo transferida por um retrovirus, o qual gera clones contendo mais de três tipos de neurônios, onde, dentre outros, contêm uma combinação de neurônios e glia de Müller, glia de Müller somente ou um simples tipo de neurônio. ${ }^{10}$ Estudos da neurogênese da retina em pequenos vertebrados têm mostrado que a geração de neurônios da retina segue uma sequência evolutiva, na qual as células ganglionares da retina, fotorreceptores cones, células horizontais e uma população de células amácrinas, nascem durante estágios iniciais da histogênese da retina, enquanto células bipolares, glia de Müller e a maioria dos fotorreceptores bastonetes nascem durante estágios finais da histogênese. ${ }^{11}$

\section{Critérios para escolher a fonte de células-tronco para transplante da retina humana}

Estudos experimentais em 1980 buscaram respostas com relação à regeneração da função visual, incluindo transplante de olhos inteiros para salamandras geneticamente sem olhos, ${ }^{12}$ implante de nervos periféricos em retina de ratos adultos ${ }^{13}$ e enxerto de retina de rato em fase embrionária em uma determinada lesão da retina de uma rato adulto. ${ }^{14}$ Desde então, muitas técnicas para regenerar a retina têm sido tentadas em vários modelos experimentais usando células -tronco derivadas de diferentes fontes. Estas incluem células derivadas do cérebro, ${ }^{15}$ células progenitoras da retina, embrionárias, epitélio ciliar e células tronco de olhos pós-natal, ${ }^{16}$ células embrionárias humanas, ${ }^{17}$ células-tronco mesenquimais do cordão umbilical, ${ }^{18}$ células-tronco derivadas da medula óssea $^{19}$ e células-tronco de Müller. ${ }^{9}$ Entretanto, apesar de intensa pesquisa neste campo, os dados ainda não são suficientes e evidentes para sabermos sobre a integração das células-tronco com a retina, sobrevida em longo prazo do enxerto, ou o grau de restauração visual.

\section{A retina neural humana}

A retina neural humana, semelhante à de qualquer mamífero, é organizada em três diferentes camadas de células nucleares que abriga seis diferentes tipos de neurônios e cerca de sessenta subtipos neuronais. A camada externa contém as células fotorreceptoras (neurônios sensíveis à luz); a camada média (também conhecida como nuclear interna) contém as células bipolares, amácrinas e células horizontais; e a camada mais interna (também conhecida por camada ganglionar) predominantemente contém as células ganglionares e células amácrinas. ${ }^{20}$ Após estímulo visual, todos os neurônios da retina sofrem uma complexa cascata de interações neurais através da ativação de caminhos sinápticos, o qual, finalmente leva ao transporte das mensagens visuais pelas células ganglionares via nervo ótico para o cérebro. Este processo complexo requer conecções intactas dos axônios, as quais são perdidas em processos degenerativos da retina e uma potencial restauração da função visual criticamente depende se os neurônios transplantados podem restabelecer a dinâmica deste caminho neural. O sucesso em potencial das terapias baseadas no uso de células-tronco pode, portanto, depender se as células implantadas podem diferenciar-se em diferentes neurônios da retina e se estes neurônios podem restabelecer os diferen- 
tes caminhos sinápticos dos neurônios dentro da retina hospedeira.

Embora um progresso significativo tenha sido feito nos anos recentes através do entendimento do mecanismo molecular, que determina a especificação das células da retina no peixe, anfíbios e pequenos vertebrados, e existe uma sobreposição na expressão de marcadores progenitores da retina humana em desenvolvimento como em outras espécies, ${ }^{5,9}$ é bem reconhecido que existe ainda muito a se aprender sobre os sinais que levam ao desenvolvimento neuronal específico no olho humano. Neste contexto, embora tipos diferentes de células-tronco possam potencialmente ser usados para regeneração da retina humana doente, pode ser mais apropriado, como sugerido em recentes estudos, ${ }^{21} \mathrm{o}$ uso de células-tronco adultas que já passaram por estágios cruciais de desenvolvimento, tornando-as comprometidas em se diferenciarem em neurônios da retina. Isto poderia desviar extensivos procedimentos que necessitariam de uma diferenciação in vitro das células embrionárias, hematopoéticas, mesenquimais ou células-tronco cerebrais em células progenitoras da retina, especialmente por não sabermos profundamente os caminhos moleculares necessários para tal diferenciação. Além disso, para o estado de diferenciação das células-tronco potencialmente usadas para o transplante, consideração especial deverá ser dada também ao meio no qual estas célulastronco serão transplantadas. Desde que a retina doente não é um meio permissivo no qual as células-tronco poderiam facilmente se integrar, o tecido danificado que necessita de reparo também necessitará de terapias adjuntas para modificar a matriz celular e facilitar a integração funcional das célulastronco. Portanto, o uso de células-tronco adultas no olho humano tem sido apresentado, e está claro que estas células podem ter vantagens em termos de aplicação clínica imediata, segurança e viabilidade para o transplante. ${ }^{22}$

\section{Caracterização e isolamento das células-tronco da retina}

As células-tronco da retina podem ser isoladas e induzir a proliferação in vitro de olhos adultos e fetais por uma dissociação enzimática, seguida por cultura na presença de fatores de crescimento, como fator de crescimento de fibroblastos (Fibroblast growth factor - FGF-R) e fator de crescimento epitelial (Epidermal growth factor - EGF-R) ${ }^{5,9}$ Diversos marcadores têm sido identificados, permitindo a caracterização destas células, incluindo nestin e BIII tubulin, ${ }^{23,24}$ bem como vários fatores de transcrição e proteínas expressadas pelas células-tronco da retina durante seu desenvolvimento in vivo. Alguns fatores conhecidos, considerados importantes para caracterizar células-tronco da retina incluem: (i) Sonic hedgehog protein (Shh), a qual, no desenvolvimento inicial, promove a diferenciação das células progenitoras em células ganglionares e age como molécula sinalizadora; (ii) Pax6, um fator regulatório que promove a multipotencialidade das células progenitoras da retina; (iii) Basic helix-loop-helix (bHLH), que são fatores de transcrição semelhantes ao Math 5 e Neuro D, os quais, após ativação, direcionam as células progenitoras para as células ganglionares e amácrinas, respectivamente; (iv) Chx 10, um dos marcadores iniciais do desenvolvimento da retina, o qual é requerido para a proliferação das células da retina e formação das células bipolares; (v) Sox2, um fator de transcrição achado na neurogênese inicial, e consiste em um regulador de diferenciação e migração das células para diferentes camadas da retina. ${ }^{23,24}$ Expressão de Sox2 tem também sido demonstrada em precursores de retina fetal humana e constitui um importante marcador de células-tronco de Müller no olho humano adulto. ${ }^{9}$ Outros fatores conhecidos para direcionar a diferenciação das células progenitoras da retina incluem os receptores para fibroblast growth factors (FGF-R) e epidermal growth factor (EGF-R), os quais possuem um papel importante na diferenciação neural e glial. ${ }^{24}$

Doenças prevalentes que podem potencialmente se beneficiar com a terapia com células-tronco

A morte da célula neural é a causa derradeira da cegueira como resultado das doenças degenerativas da retina, incluindo degeneração macular relacionada com a idade (DMRI), retinopatia diabética proliferativa (RDP), estádios avançados de glaucoma, retinose pigmentar (RP), vitreorretinopoatia proliferativa (PVR) e doenças hereditárias da retina. A DMRI é a principal causa de cegueira, acima dos 50 anos de idade, no mundo ocidental, afetando de 20 a $25 \mathrm{mi}-$ lhões de pessoas em todo o mundo. ${ }^{25}$ É estimado que, entre 200 mil e 300 mil indivíduos no Reino Unido são cegos ou parcialmente cegos como resultado da DMRI. ${ }^{25} \mathrm{Na}$ Inglaterra, a retinopatia diabética é a maior causa de cegueira entre 16 e 64 anos de idade, afetando mais de 35\% dos indivíduos com mais de vinte anos de diabetes. ${ }^{26}$ Até o momento, tratamento com utilização de fatores antiangiogênicos, fotocoagulação a laser, e tratamentos cirúrgicos são somente hábeis em atrasar a perda visual nestes pacientes, mas, a longo prazo, é praticamente impossível evitar que uma perda visual ocorra no final. Assim, a esperança atual da restauração da função visual nestes pacientes está no desenvolvimento de terapias baseadas em células-tronco para substituir os neurônios danificados, o que poderia potencialmente, integrar a rede neural remanescente.

\section{Epitélio pigmentado da retina (EPR)}

O EPR constitui-se de uma monocamada de células pigmentadas aderidas à superfície interna da membrana de Bruch. Está diretamente posicionada sobre os segmentos externos dos fotorreceptores e possui um papel importante na homeostase retiniana. ${ }^{27} \mathrm{~A}$ disfunção do EPR ocorre em diversas doenças da retina, como a RP e DMRI ${ }^{28}$ para as quais o transplante de células-tronco para regenerar as células 
do EPR podem constituir uma abordagem promissora para o tratamento destas doenças

Avanços maiores no desenvolvimento da terapia com células-tronco para regenerar o EPR têm sido feitos durante os últimos anos, com os achados de que as células-tronco embrionárias humanas promovem uma fonte bem caracterizada e reproduzível de EPR que poderia ser potencialmente usada em estudos clínicos humanos. ${ }^{29}$ Transplante de EPR derivado de células-tronco embrionárias em modelos animais de degeneração tem demonstrado melhorar a sobrevida dos fotorreceptores. ${ }^{30}$ Com base neste achado, extensas pesquisas no potencial das células-tronco em regenerar as células do EPR para transplante em pacientes com RP e DMRI estão sendo ativamente propostas em diferentes grupos. As células do EPR humano derivadas de células embrionárias não foram ainda usadas em estudo clínico, mas, com a tecnologia e conhecimento disponíveis no presente, não está longe a possibilidade de aplicação destas células em terapias humanas. Entretanto, como qualquer outra terapia celular, a geração destas células necessita ser realizada sob condições terapêuticas, com segurança e necessidade de uma avaliação imunogética antes de ser aplicada em tratamentos humanos.

\section{Utilização de células-tronco adultas na terapia de doenças da retina}

Otani e cols..$^{31}$ reportaram que Lin- HSCs injetadas diretamente dentro do olho poderiam ativar astrócitos e participar no desenvolvimento da angiogênese em ratos no período neonatal ou em ratos adultos com neovascularização induzida por uma injúria. Estes autores também reportaram que células-tronco derivadas da medula óssea (Lin- HSCs), quando injetadas intravítreo duas semanas pós-natal poderiam prevenir completamente degeneração vascular retiniana observada em modelos de ratos de degeneração retiniana (tipo rd1 e rd 10). Neste mesmo estudo foi observado que este salvamento vascular correlacionou com o salvamento neuronal. Foi demonstrado que a camada nuclear interna permaneceu próxima do normal, e a camada nuclear externa, que contém os fotorreceptores, estava significativamente preservada com salvamento das células contendo predominantemente cones. No estudo eletrorretinográfico (ERG) foram notadas respostas presentes nos ratos que foram submetidos ao tratamento e respostas ausentes no grupo controle.

Outro achado neste estudo foi que a análise dos genomas dos olhos tratados e não tratados revelou um aumento de expressão dos genes apoptóticos. Estes achados demonstraram que os efeitos neurotróficos correlacionam com preservação da vasculatura, sugerindo que as célulastronco derivadas da medula óssea podem ser utilizadas no tratamento de doenças como degenerações e vasculopatias retinianas que atualmente não possuem tratamento eficaz.

Avaliamos recentemente ${ }^{32}$ o comportamento das células-tronco derivadas da medula óssea em olhos de coe- lhos com injúrias coriorretinianas induzidas por laser diodo $670 \mathrm{~nm}$. Cinquenta coelhos da raça New Zealand, pesando aproximadamente de 2,0 a 2,5 kg foram selecionados para o estudo. O experimento foi aprovado pelo comitê de ética médica de acordo com as normas da Association for Research in Vision and Ophthalmology (ARVO) para uso de animais em pesquisa oftalmológica. Uma injeção intravítrea de célulastronco derivadas da medula óssea foi realizada 24 horas após a indução de lesões coriorretinianas com laser diodo com comprimento de onda de 670nm (Figura 1) na área temporal da retina. Noventa dias após o procedimento, o comportamento regenerativo produzido pelas células-tronco foi estudado no nível do tecido coriorretiniano através da microscopia ótica e eletrônica (Figura 2). A cicatrização obtida pelos coelhos que receberam as células-tronco foi comparada com um grupo controle de coelhos que receberam também 50 impactos de laser, porém sem implante das células-tronco. Os resultados obtidos nos cortes histológicos dos olhos enucleados dos coelhos mostraram alterações a nível dos tecidos coriorretinianos após noventa dias desde a aplicação dos

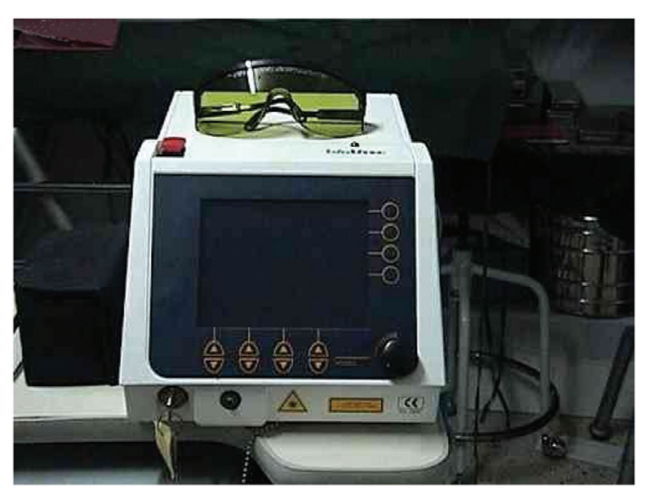

Figura 1. As lesões coriorretinianas foram realizadas com laser diodo $670 \mathrm{~nm}(\mathrm{P}=600 \mathrm{~mW}, \varnothing=100 \mathrm{~m}, 1 \mathrm{~s})$

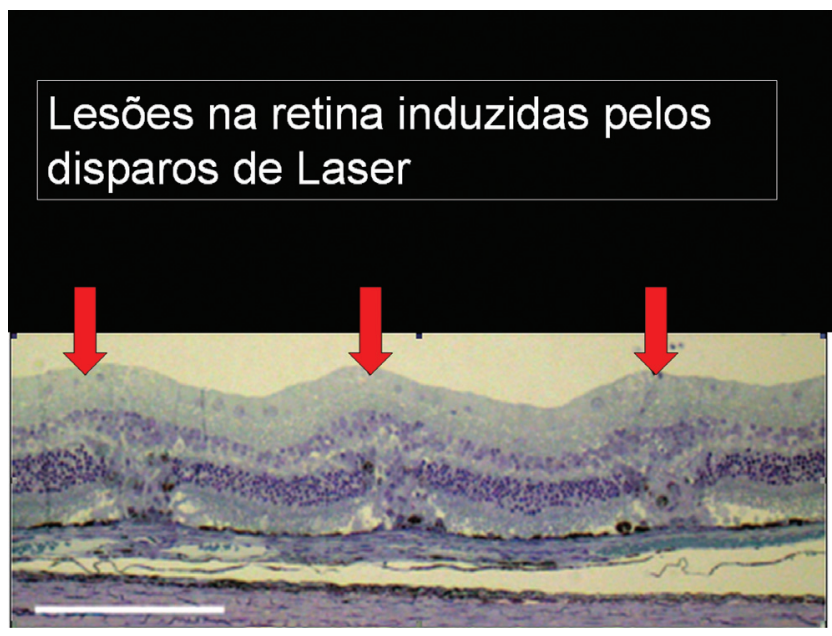

Figura 2. Imagem histológica da retina do coelho um mês após realizaçao de impactos do laser. Observa-se a irregularidade do tecido retiniano (flechas) 


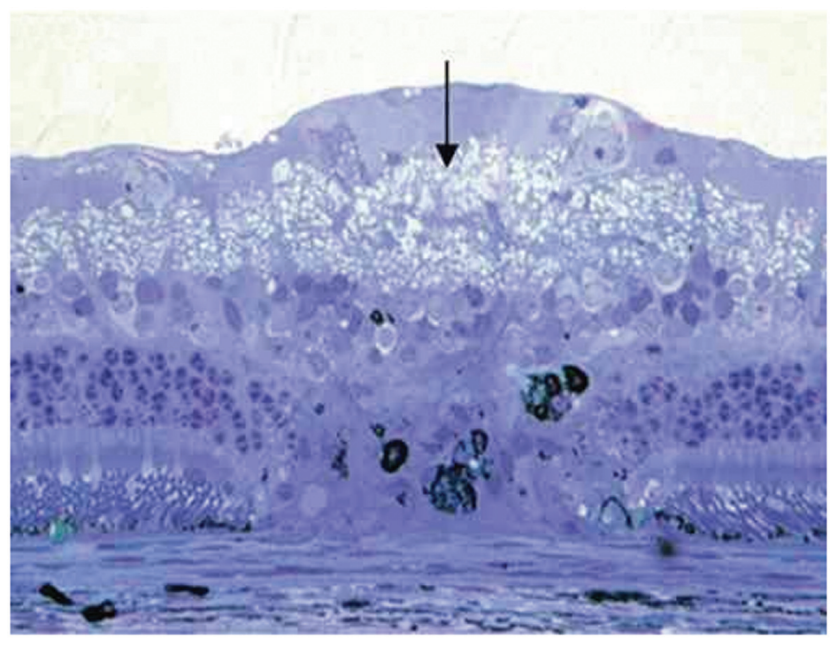

Figura 3. Imagem histológica da retina de um coelho do grupo controle, observada 90 dias após a realização dos impactos de laser. Observamos uma grande área de gliose cicatrizal (flecha)

impactos. Nós observamos em 23 coelhos a recuperação de $90 \%$ das cicatrizes coriorretinianas $(\mathrm{n}=45$ impactos recuperados), dois coelhos apresentaram 50\% de recuperação ( $n=25$ impactos recuperados), em três coelhos observamos a recuperação de $42 \%$ ( $n=21$ impactos recuperados) e em dois coelhos observamos $36 \%$ de recuperação dos impactos $(n=18)$. No grupo controle onde não foram implantadas as célulastronco, observamos uma grande formação de gliose a nível do tecido coriorretiniano com halo de hiperplasia do epitélio pigmentado da retina ao redor da área de gliose impossibilitando considerar áreas de recuperação (Figura 3). Portanto, demonstramos neste estudo o potencial da injeção intravítrea de células-tronco autólogas derivadas da medula óssea na recuperação da morfologia das células coriorretinianas em processo de sofrimento.

Recentemente, Jonas ${ }^{33}$ e colaboradores realizaram injeção intravítrea de células-tronco derivadas da medula óssea em um paciente com sequela de oclusão vascular da retina e demonstraram que o procedimento é viável e seguro para ser realizado em ser humano pois não houve sinais de infecção, inflamação ou desenvolvimento de formação tumoral intraocular.

\section{Córnea}

Células-tronco e o epitélio da córnea

A transparência da córnea e, portanto, a acuidade visual depende da integridade e status funcional de suas camadas e, dentre elas, o epitélio da córnea. As células-tronco do epitélio da córnea residem na junção entre a córnea e a conjuntiva, região esta denominada de limbo. Estas células, conhecidas como células-tronco do epitélio límbico (limbal epithelial stem cell-LESC) são responsáveis pela manutenção do epitélio da córnea durante a vida. Quando as células-tronco do limbo dividem-se em resposta à perda celular homeostática, dá origem às células transitórias que migram, proliferam e se diferenciam para popular o epitélio da córnea. Evidência que o limbo da córnea seria fonte de células-tronco adultas foi primeiro sugerido, por observações no início dos anos 70, que o pigmento no epitélio de olhos fortemente pigmentados migravam em linhas do limbo para a região central da córnea e cicatrizavam defeitos epiteliais. ${ }^{30}$ A existência de um ciclo lento de células basais do epitélio límbico foi mais tarde confirmado por observações que as células localizadas no limbo retinham o marcador tritiated thymidine por longo período de tempo, uma característica de células-tronco de ciclo lento. ${ }^{34}$ Através de um exame detalhado do limbo da córnea foi demonstrado recentemente a existência de estruturas topograficamente características associadas com depósitos concentrados de LESCs, o qual predominantemente ocorre no limbo superior e inferior. ${ }^{35}$ Isto é interessante especular que estas regiões, as quais normalmente são cobertas pelas pálpebras superiores e inferiores, estão envolvidas para propiciar um grau de proteção das células-tronco de insultos do meio ambiente, como a luz ultravioleta.

\section{Abordagens atuais para terapia celular da córnea com células-tronco}

Anormalidade na superfície ocular decorrente de uma deficiência de LESC pode ocorrer como resultado de uma doença hereditária do olho, mas mais comumente como resultado de fatores adquiridos, incluindo queimadura química, ceratopatia por lente de contato, inflamação crônica do limbo, cirurgia no limbo e síndrome de Stevens-Johnson. Quando a deficiência ocorre no epitélio da conjuntiva vizinha, o qual é impedido de invadir o epitélio da córnea pelas LESCs, migram para a superfície ocular por um processo denominado de conjuntivalização. Quando isto acontece, o paciente pode experimentar repetidas erosões epiteliais, crescimento de vasos sanguíneos através da córnea normalmente avascular, inflamação, dor, e, finalmente, perda visual. Abordagens clínicas para tratamento da deficiência de LESC incluem transplante autólogo do tecido do limbo do olho contralateral sadio para o olho doente. Embora com possibilidade de sucesso, este procedimento apresenta risco de criar deficiência de LESC no olho doador. ${ }^{36}$ Alternativamente, o enxerto de tecido límbico tem sido realizado utilizandose material doador de cadáver. Entretanto, devido à abundância de antígenos HLA-DR e células de Langerhans no enxerto, os pacientes necessitam ser submetidos a imunossupressão sistêmica por um período prolongado. Em 1997, a primeira terapia com células cultivadas com sucesso para deficiência de LESC foi relatada em dois pacientes com queimadura química. ${ }^{1} \mathrm{O}$ procedimento envolveu o isolamento e expansão ex vivo de LESC autólogo de $1 \mathrm{~mm}$ para $2 \mathrm{~mm}^{2} \mathrm{de}$ biópsia límbica para transplante. O resultado clínico foi pro- 
missor com ambos os pacientes experimentando melhora visual por pelo menos dois anos. ${ }^{1}$ Desde então, um número de centros ao redor do mundo tem empregado esta técnica usando uma variedade de diferentes protocolos para cultura de célula e sistemas de transporte para transferir as células para o paciente, incluindo o uso de células cultivadas de LESC alógenas de olhos de cadáveres. ${ }^{37}$

Os vários métodos e os resultados envolvendo terapia com LESC foram avaliados recentemente. ${ }^{38}$ A proporção de sucesso dos resultados combinados de culturas de LESC autólogo e alógeno para terapia é de aproximadamente $70 \%$. Devemos obviamente ressaltar que a interpretação destes resultados apresenta limitações, como diferentes etiologias da falência do enxerto da LESC, protocolos de cultivo adotados variados, intervenções cirúrgicas oculares prévias e condutas diferentes no pré e pós-operatório. Apesar destas limitações, os dados sugerem que a terapia com cultura de LESC é uma benéfica opção para tratamento das doenças da superfície ocular.

Até o presente, existe muita pesquisa centrada na avaliação de fontes alternativas de células-tronco para terapia celular da córnea, incluindo células-tronco embrionárias. ${ }^{39}$ Uma fonte de célula autóloga de interesse significativo é a célula epitelial da mucosa oral. As primeiras reportagens do uso destas células para tratamento de pacientes com deficiência de LESC mostraram inicialmente resultados promissores, mas, subsequentemente, estudos têm demonstrado que a neovascularização pode ocorrer em alguns pacientes após este transplante. ${ }^{40}$ Isto indica que existe ainda muita coisa a ser compreendida entre as interações das células-tronco límbicas em seu ambiente com respeito à sua regulação e função.

\section{Outras células progenitoras no olho}

Observações recentes mostraram que a conjuntiva é também uma fonte de células-tronco. Um estudo in vitro detalhado de propriedades clonogênicas do epitélio da superfície ocular revelou uma distribuição uniforme de células-tronco na conjuntiva bulbar e do fórnix. ${ }^{43}$ Eles demonstraram que o epitélio conjuntival e células caliciformes derivam de um progenitor comum com alta capacidade proliferativa, que dá um aumento nas células caliciformes até duas vezes durante a vida. Progenitores de células epiteliais da conjuntiva foram cultivadas in vitro na membrana amniótica e mostraram que, semelhante à LESC, apresentam um ciclo lento e retêm marcadores. Células epiteliais da conjuntiva cultivadas podem conter uma proporção de células-tronco e têm sido usadas com sucesso para tratamento de pacientes com doenças da superfície ocular. ${ }^{44}$

O EPR e o epitélio pigmentado da iris (EPI) de olhos humanos, bem como as células da esclera e coróide, apresentaram, em uma diferenciação in vitro, uma expressão de antígenos de neurônios da retina. Entretanto, a capacidade de uma renovação celular a longo prazo e evidência que elas constituem uma verdadeira população de células-tronco não foi ainda provada. Além disso, existe alguma evidência que as LESC exibem uma plasticidade neural,${ }^{45}$ levantando a possibilidade de se explorarem estas células para gerar progenitores da retina.

Outro estudo recente tem identificado uma população de progenitores de ceratócitos no estroma da córnea em olhos humanos. Células progenitoras derivadas da córnea de ratos C57BL6/J são hábeis em formar esferas, expressar PAX6 e manter seu fenótipo do ceratócito após diversas passagens. ${ }^{46}$ Similarmente, células do estroma isolado da região da córnea próxima ao limbo expressam PAX6, e a proteína transportadora ABCG2 foi observada em muitas células-tronco. Sobre uma cultura de FGF2, eles expressam marcadores de ceratócitos e, após a diferenciação, eles adquirem características condrogênicas e neurogênicas ${ }^{47}$ indicando a habilidade multipotente destas células. Estes achados sugerem que o progenitor do ceratócito tem um potencial para uso em terapia baseada em células para tratar muitas doenças da córnea, e a exploração desta capacidade poderia oferecer um avanço na terapia baseada em células para tratamento de doenças da superfície ocular. ${ }^{22,48}$

\section{Conclusões}

A terapia baseada com células-tronco para regeneração e reparo ocular constitui uma esperança para a restauração da função visual em indivíduos com tecidos oculares irreversivelmente danificados por doença ou trauma. Até o presente momento, somente as células LESC para o reparo da córnea apresentam aplicação clínica reconhecida no campo da oftalmologia. Experiências adquiridas com esta abordagem poderão potencialmente ajudar com o desenho de terapias baseadas em células-tronco para regenerar outros tecidos oculares, particularmente a retina. Existe muita especulação na capacidade de novas fontes descobertas de progenitores da retina, mas, antes de estabelecermos qualquer nova terapia, deveríamos entender a real potencialidade de cada fonte de célula para regenerar os neurônios da retina. Problemas para serem solucionados incluem padronização dos métodos de isolamento e expansão para preservar os fenótipos das células-tronco, a identificação dos requisitos para diferenciação neural e preparação de andaimes para o enxerto, modulação de matriz extracelular para promover a migração celular e sinapse neural, prevenção de rejeição imune e desenvolvimento de tumor e, mais importante, a identificação de condições que mantenham a sobrevida do enxerto. Apesar de muitos problemas práticos, existe um otimismo geral entre a comunidade médica e científica que a terapia baseada nas células-tronco para restaurar a função visual pode tornar-se realidade em um futuro não muito distante. 


\begin{abstract}
Advances in the field of stem cell therapy have provided promising results in the regeneration of tissues damaged by eye diseases for which treatment is so far unavailable. Therapy based on stem cells to regenerate and repair is a hope for the restoration of visual function in individuals with ocular tissue irreversibly damaged by disease or trauma. Until now, only limbal epithelial stem cells have a recognized clinical application in ophthalmology for the repair of the cornea. Experience gained with this approach, may potentially help with the design of therapies based on stem cells to regenerate other eye tissues, in particular the retina. The use of adult stem cells to treat degenerative diseases of the retina has been tested in animals, as has their feasibility for use in humans. Although many practical problems exist, there is general optimism among the medical and scientific community that therapy based on stem cells to restore visual function can become a reality in the not too distant future. This article reviews the current status and limitations of the application of stem cell therapy in the eye and considers future prospects of its use in the restoration of vision Rev. Bras. Hematol. Hemoter. 2009;31(Supl. 1):120-127.
\end{abstract}

Key words: Retinal stem cells; Müller stem cells; limbal epithelial stem cells; retina; cornea.

\section{Referências Bibliográficas}

1. Pellegrini G, Traverso CE, Franzi AT, Zingirian M, Cancedda R, De Luca M. Long-term restoration of damaged corneal surfaces with autologous cultivated corneal epithelium. Lancet. 1997;349 (9057):990-3.

2. Graw J. Genetic aspects of embryonic eye development in vertebrates. Dev Genet. 1996;18(3):181-97.

3. Raymond PA, Hitchcock PF. Retinal regeneration: common principles but a diversity of mechanisms. Adv Neurol. 1997; 72: 171-84.

4. Moshiri A, Close J, Reh TA. Retinal stem cells and regeneration. Int J Dev Biol. 2004;48(8-9):1003-14.

5. Coles BL, Angénieux B, Inoue T, Del Rio-Tsonis K, Spence JR, McInnes RR, et al. Facile isolation and the characterization of human retinal stem cells. Proc Natl Acad Sci USA. 2004;101 (44): $15772-7$

6. Fischer AJ, Reh TA. Müller glia are a potential source of neural regeneration in the postnatal chicken retina. Nat Neurosci. 2001; 4(3):247-52.

7. Das AV, Mallya KB, Zhao X, Ahmad F, Bhattacharya S, Thoreson WB, et al. Neural stem cell properties of Müller glia in the mammalian retina: regulation by Notch and Wnt signaling. Dev Biol. 2006;299(1):283-302

8. Raymond PA, Barthel LK, Bernardos RL, Perkowski JJ. Molecular characterization of retinal stem cells and their niches in adult zebrafish. BMC Dev Biol. 2006;6:36.

9. Lawrence JM, Singhal S, Bhatia B, Keegan DJ, Reh TA, Luthert PJ, et al. MIO-M1 cells and similar muller glial cell lines derived from adult human retina exhibit neural stem cell characteristics. Stem Cells. 2007;25(8):2033-43.

10. Cepko CL, Austin CP, Yang X, Alexiades M, Ezzeddine D. Cell fate determination in the vertebrate retina. Proc Natl Acad Sci USA. 1996;93(2):589-95.
11. Marquardt T, Gruss P. Generating neuronal diversity in the retina: one for nearly all. Trends Neurosci. 2002;25(1):32-8.

12. Harris WA. The transplantation of eyes to genetically eyeless salamanders: visual projections and somatosensory interactions. J Neurosci. 1982;2(3):339-53.

13. So KF, Aguayo AJ. Lengthy regrowth of cut axons from ganglion cells after peripheral nerve transplantation into the retina of adult rats. Brain Res. 1985;328(2):349-54.

14. Turner JE, Blair JR. Newborn rat retinal cells transplanted into a retinal lesion site in adult host eyes. Brain Res. 1986;391(1):91-104.

15. Young MJ, Ray J, Whiteley SJ, Klassen H, Gage FH. Neuronal differentiation and morphological integration of hippocampal progenitor cells transplanted to the retina of immature and mature dystrophic rats. Mol Cell Neurosci. 2000;16(3):197205.

16. Chacko DM, Das AV, Zhao X, James J, Bhattacharya S, Ahmad I. Transplantation of ocular stem cells: the role of injury in incorporation and differentiation of grafted cells in the retina. Vision Res. 2003;43(8):937-46.

17. Banin E, Obolensky A, Idelson M, Hemo I, Reinhardtz E, Pikarsky $\mathrm{E}$, et al. Retinal incorporation and differentiation of neural precursors derived from human embryonic stem cells. Stem Cells. 2006;24(2):246-57.

18. Lund RD, Wang S, Lu B, Girman S, Holmes T, Sauvé Y, et al. Cells isolated from umbilical cord tissue rescue photoreceptors and visual functions in a rodent model of retinal disease. Stem Cells. 2007;25(3):602-11.

19. Otani A, Dorrell MI, Kinder K, Moreno SK, Nusinowitz S, Banin $\mathrm{E}$, et al. Rescue of retinal degeneration by intravitreally injected adult bone marrow-derived lineage-negative hematopoietic stem cells. J Clin Invest. 2004;114(6):765-74.

20. Masland RH. Neuronal cell types. Curr Biol. 2004;14 (13): R497-500.

21. MacLaren RE, Pearson RA, MacNeil A, Douglas RH, Salt TE, Akimoto $\mathrm{M}$, et al. Retinal repair by transplantation of photoreceptor precursors. Nature. 2006;444(7116):203-7.

22. Limb GA, Daniels JT. Ocular regeneration by stem cells: present status and future prospects. Br Med Bull. 2008;85:47-61.

23. AAhmad I, Das AV, James J, Bhattacharya S, Zhao X. Neural stem cells in the mammalian eye: types and regulation. Semin Cell Dev Biol. 2004;15(1):53-62.

23. Fischer AJ, Reh TA. Growth factors induce neurogenesis in the ciliary body. Dev Biol. 2003;259(2):225-40.

24. Chopdar A, Chakravarthy U, Verma D. Age related macular degeneration. BMJ. 2003;326(7387):485-8.

25. Kohner EM, Aldington SJ, Stratton IM, Manley SE, Holman RR, Matthews DR, et al. United Kingdom Prospective Diabetes Study, 30: diabetic retinopathy at diagnosis of non-insulin-dependent diabetes mellitus and associated risk factors. Arch Ophthalmol. 1998;116(3):297-303.

26. Strauss O. The retinal pigment epithelium in visual function. Physiol Rev. 2005;85(3):845-81.

27. Nowak JZ. Age-related macular degeneration (AMD): pathogenesis and therapy. Pharmacol Rep. 2006;58(3):353-63.

28. Klimanskaya I, Hipp J, Rezai KA, West M, Atala A, Lanza R. Derivation and comparative assessment of retinal pigment epithelium from human embryonic stem cells using transcriptomics. Cloning Stem Cells. 2004;6(3):217-45.

29. Lund RD, Wang S, Klimanskaya I, Holmes T, Ramos-Kelsey R, Lu $\mathrm{B}$, et al. Human embryonic stem cell-derived cells rescue visual function in dystrophic RCS rats. Cloning Stem Cells. 2006;8 (3):189-99 
30. Davanger M, Evensen A. Role of the pericorneal papillary structure in renewal of corneal epithelium. Nature. 1971;229(5 286):560-1.

31. Otani A, Kinder K, Ewalt K, Otero FJ, Schimmel P, Friedlander M. Bone marrow-derived stem cells target retinal astrocytes and can promote or inhibit retinal angiogenesis. Nat Med. 2002; 8(9):1004-10.

32. Siqueira RC, Abad L, Benson G, Sami M. Behaviour of stem cells in eyes of rabbits with chorioretinal injuries caused by laser red diode 670N-M. In: Annual Meeting of the Association for Research in Vision and Ophthalmology (ARVO), 2008, Fort Lauderdale. Investigative Ophthalmology \& Visual Sciences. 2008;49:536-536.

33. Jonas JB, Witzens-Harig M, Arseniev L, Ho AD. Intravitreal autologous bone marrow-derived mononuclear cell transplantation: a feasibility report. Acta Ophthalmol. 2008;86(2):225-6.

34. Cotsarelis G, Cheng SZ, Dong G, Sun TT, Lavker RM. Existence of slow-cycling limbal epithelial basal cells that can be preferentially stimulated to proliferate: implications on epithelial stem cells. Cell. 1989;57(2):201-9.

35. Shortt AJ, Secker GA, Munro PM, Khaw PT, Tuft SJ, Daniels JT Characterization of the limbal epithelial stem cell niche: novel imaging techniques permit in vivo observation and targeted biopsy of limbal epithelial stem cells. Stem Cells. 2007;25(6):1402-9.

36. Jenkins C, Tuft S, Liu C, Buckley R. Limbal transplantation in the management of chronic contact-lens-associated epitheliopathy. Eye. 1993;7( Pt 5):629-33.

37. James SE, Rowe A, Ilari L, Daya S, Martin R. The potential for eye bank limbal rings to generate cultured corneal epithelial allografts. Cornea. 2001;20(5):488-94

38. Shortt AJ, Secker GA, Notara MD, Limb GA, Khaw PT, Tuft SJ, et al. Transplantation of ex vivo cultured limbal epithelial stem cells: a review of techniques and clinical results. Surv Ophthalmol. 2007;52(5):483-502.

39. Ahmad S, Stewart R, Yung S, Kolli S, Armstrong L, Stojkovic M, et al. Differentiation of human embryonic stem cells into corneal epithelial-like cells by in vitro replication of the corneal epithelial stem cell niche. Stem Cells. 2007;25(5):1145-55.

40. Nishida K, Yamato M, Hayashida Y, Watanabe K, Yamamoto K, Adachi E, et al. Corneal reconstruction with tissue-engineered cell sheets composed of autologous oral mucosal epithelium. N Engl J Med. 2004;351(12):1187-96
41. Chee KY, Kicic A, Wiffen SJ. Limbal stem cells: the search for a marker. Clin Experiment Ophthalmol. 2006;34(1):64-73.

42. Daya SM, Watson A, Sharpe JR, Giledi O, Rowe A, Martin R, et al. Outcomes and DNA analysis of ex vivo expanded stem cell allograft for ocular surface reconstruction. Ophthalmology. 2005;112 (3):470-7.

43. Pellegrini G, Golisano O, Paterna P, Lambiase A, Bonini S, Rama P, et al. Location and clonal analysis of stem cells and their differentiated progeny in the human ocular surface. J Cell Biol. 1999;145(4):769-82.

44. Dogru M, Tsubota K. Survival analysis of conjunctival limbal grafts and amniotic membrane transplantation in eyes with total limbal stem cell deficiency. Am J Ophthalmol. 2005;140(2):305-6.

45. Zhao X, Das AV, Thoreson WB, James J, Wattnem TE, RodriguezSierra J, et al. Adult corneal limbal epithelium: a model for studying neural potential of non-neural stem cells/progenitors. Dev Biol. 2002;250(2):317-31.

46. Yoshida S, Shimmura S, Shimazaki J, Shinozaki N, Tsubota K. Serum-free spheroid culture of mouse corneal keratocytes. Invest Ophthalmol Vis Sci. 2005;46(5):1653-8.

47. Du Y, Funderburgh ML, Mann MM, SundarRaj N, Funderburgh JL. Multipotent stem cells in human corneal stroma. Stem Cells. 2005;23(9):1266-75.

48. Daniels JT, Secker GA, Shortt AJ, Tuft SJ, Seetharaman S. Stem cell therapy delivery: treading the regulatory tightrope. Regen Med. 2006;1(5):715-9.

Avaliação: O tema apresentado consta da pauta elaborada pelo editor, Professor Milton Artur Ruiz, e coeditores deste suplemento, Professores Sergio Paulo Bydlowski e Adriana Seber.

Conflito de interesse: não declarado

Recebido: 26/07/2008

Aceito: $13 / 10 / 2008$ 